\title{
Testing for Induction of Clindamycin Resistance in Erythromycin-Resistant Isolates of Staphylococcus aureus
}

\author{
Christine D. Steward, ${ }^{1}$ Patti M. Raney, ${ }^{1}$ Allison K. Morrell, ${ }^{1}$ Portia P. Williams, ${ }^{2}$ \\ Linda K. McDougal, ${ }^{1}$ Laura Jevitt, ${ }^{1}$ John E. McGowan, Jr., ${ }^{2}$ \\ and Fred C. Tenover ${ }^{1 *}$ \\ Division of Healthcare Quality Promotion, Centers for Disease Control and Prevention, Atlanta, GA 30333, ${ }^{1}$ and \\ Department of Epidemiology, Rollins School of Public Health, Emory University, Atlanta, GA 30322 2
}

Received 8 September 2004/Returned for modification 9 November 2004/Accepted 20 December 2004

Disk diffusion and broth microdilution (BMD) were used to perform clindamycin (CLI) induction testing on 128 selected nonduplicate isolates of Staphylococcus aureus. Disk diffusion testing involved placing CLI and erythromycin (ERY) disks approximately $12 \mathrm{~mm}$ apart (measured edge to edge) on a Mueller-Hinton agar plate that had been inoculated with an $S$. aureus isolate; the plate was then incubated for 16 to $18 \mathrm{~h}$. Two distinct induction phenotypes (labeled $\mathrm{D}$ and $\mathrm{D}^{+}$) and four noninduction phenotypes (designated as negative [Neg], hazy $D$ zone $[H D]$, resistant $[R]$, and susceptible $[S]$ ) were observed in disk diffusion results. A clear, Dshaped zone of inhibition around the CLI disk was designated as the D phenotype and was observed for 21 isolates while a D-shaped zone containing inner colonies growing up to the CLI disk was designated as $\mathrm{D}^{+}(17$ isolates). In addition, 10 isolates were CLI susceptible and ERY resistant but were not inducible and showed no blunting of the CLI zone (Neg phenotype). Isolates that were CLI and ERY resistant (constitutive macrolide-lincosamide-streptogramin $B$ resistance) demonstrated either a double zone of inhibition with an inner ring of reduced growth up to the edge of the disks (HD phenotype; 33 isolates) or solid growth around the CLI and ERY disks (R phenotype; 16 isolates). Finally, 31 isolates were susceptible by disk testing to both CLI and ERY (S phenotype). PCR results showed that isolates with a $\mathrm{D}$ phenotype harbored $e r m A$, isolates with a $\mathrm{D}^{+}$ phenotype contained either erm C (16 isolates) or erm $A$ and erm C (one isolate), and all 10 isolates with a Neg phenotype contained $m s r A$. All isolates with an HD or $\mathrm{R}$ phenotype harbored at least one erm gene. Isolates showing the $\mathrm{D}^{+}$phenotype by disk diffusion were also detected by BMD using a variety of CLI and ERY concentrations; however, isolates with the D phenotype were more difficult to detect by BMD and will likely require optimization of ERY and CLI concentrations in multilaboratory studies to ensure adequate sensitivity. Thus, at present, disk diffusion is the preferred method for testing $S$. aureus isolates for inducible CLI resistance.

Erythromycin (ERY) (a macrolide) and clindamycin (CLI) (a lincosamide) represent two distinct classes of antimicrobial agents that inhibit protein synthesis by binding to the $50 \mathrm{~S}$ ribosomal subunits of bacterial cells. In staphylococci, resistance to both of these antimicrobial agents can occur through methylation of their ribosomal target site (25). Such resistance is typically mediated by erm genes. Resistance to macrolides also can occur by efflux, typically mediated by the $m s r A$ gene (16). Another resistance mechanism, inactivation of lincosamides by chemical modification (such as mediated by the inu $A$ gene), appears to be rare $(1,8,15)$. The target site modification mechanism, also called macrolide-lincosamide-streptogramin $\mathrm{B}\left(\mathrm{MLS}_{\mathrm{B}}\right)$ resistance, results in resistance to ERY, CLI, and streptogramin B. This mechanism can be constitutive, where the rRNA methylase is always produced, or can be inducible, where methylase is produced only in the presence of an inducing agent. ERY is an effective inducer, but CLI is a weak inducer. In vitro, Staphylococcus aureus isolates with constitutive resistance are resistant to ERY and CLI, and isolates with inducible resistance are resistant to ERY but appear suscep-

\footnotetext{
* Corresponding author. Mailing address: Division of Healthcare Quality Promotion (G08), Centers for Disease Control and Prevention, 1600 Clifton Road, NE, Atlanta, GA 30333. Phone: (404) 6393375. Fax: (404) 639-1381. E-mail: fnt1@cdc.gov.
}

tible to CLI. In vivo, therapy with CLI may select for constitutive erm mutants (7), which may lead to clinical failure (2, 20, 24). Isolates with $m s r A$-mediated efflux also appear ERY resistant and CLI susceptible by in vitro tests; however, such isolates do not typically become CLI resistant during therapy.

An in vitro induction test can distinguish staphylococci that have inducible erm-mediated resistance from those with $\mathrm{msrA}$ mediated resistance. The test is performed by disk diffusion, placing a $15-\mu \mathrm{g}$ ERY disk in proximity to a $2-\mu \mathrm{g}$ CLI disk on an agar plate that has been inoculated with a staphylococcal isolate; the plate is then incubated overnight $(5,9,22,23)$. A flattening of the zone of inhibition around the CLI disk proximal to the ERY disk (producing a zone of inhibition shaped like the letter D) is considered a positive result and indicates that the ERY has induced CLI resistance (a positive "D-zone test"). For ERY-resistant isolates, induction tests can help laboratories determine whether results for CLI should be reported as susceptible (when the induction test is negative) or as resistant (when the induction test is positive). In January 2004, NCCLS published a procedure for CLI induction testing in which CLI disks are placed 15 to $26 \mathrm{~mm}$ from an ERY disk either as part of a standard disk diffusion procedure or on an inoculum check agar plate (13). In pilot studies carried out at the Centers for Disease Control and Prevention, we noted 
TABLE 1. Characteristics of clindamycin induction test phenotypes as tested by disk diffusion

\begin{tabular}{|c|c|c|c|c|}
\hline $\begin{array}{l}\text { Induction test } \\
\text { phenotype }\end{array}$ & $\begin{array}{l}\text { Resistance } \\
\text { phenotype }\end{array}$ & $\begin{array}{l}\text { CLI } \\
\text { result }\end{array}$ & $\begin{array}{l}\text { ERY } \\
\text { result }\end{array}$ & Induction test description \\
\hline $\mathrm{D}$ & Inducible $\mathrm{MLS}_{\mathrm{B}}$ & S & $\mathrm{R}$ & Blunted, D-shaped clear zone around CLI disk proximal to the ERY disk (Fig. 1A). \\
\hline $\mathrm{D}^{+}$ & Inducible $\mathrm{MLS}_{\mathrm{B}}$ & $\mathrm{S}$ & $\mathrm{R}$ & $\begin{array}{l}\text { Blunted, D-shaped zone around CLI disk proximal to the ERY disk and small colonies } \\
\text { growing to CLI disk in otherwise clear zone (Fig. 1B). }\end{array}$ \\
\hline Neg & $\mathrm{MS}_{\mathrm{B}}$ & $\mathrm{S}$ & $\mathrm{R}$ & Clear zone around CLI disk (Fig. 1C). \\
\hline HD & Constitutive $\mathrm{MLS}_{\mathrm{B}}$ & $\mathrm{R}$ & $\mathrm{R}$ & $\begin{array}{l}\text { Two zones of growth appear around the CLI disk. One zone is a light, hazy growth extending } \\
\text { from the CLI disk to the second zone where the growth is much heavier. The inner, hazy } \\
\text { zone is blunted proximal to the ERY disk as in phenotype D (Fig. 1D). }\end{array}$ \\
\hline $\mathrm{R}$ & Constitutive $\mathrm{MLS}_{\mathrm{B}}$ & $\mathrm{R}$ & $\mathrm{R}$ & No hazy zone. Growth up to CLI and ERY disks (Fig. 1E). \\
\hline S & No resistance & S & S & Clear, susceptible zone diameters (Fig. 1F). \\
\hline
\end{tabular}

several different D-zone phenotypes that have not been described in the literature. Furthermore, we were interested in trying to establish a broth microdilution (BMD) correlate to the CLI disk induction test.

In the present study (which was completed prior to publication of the NCCLS recommendations for clindamycin induction testing), isolates of $S$. aureus were tested with ERY and CLI alone and in combination (induction testing) by disk diffusion and broth microdilution. Results of the two methods were then correlated with the presence of erm and $m s r A$ determinants.

\section{MATERIALS AND METHODS}

Bacterial isolates. This study included 117 nonduplicate isolates of S. aureus from the culture collections of the Centers for Disease Control and Prevention and Project ICARE $(4,10)$, eight isolates donated by H. de Lencastre (Rockefeller University, New York, NY), and three PCR control isolates. Isolates of $S$. aureus (including both oxacillin-resistant and oxacillin-susceptible isolates) were selected to represent a variety of CLI induction test results.

Antimicrobial susceptibility testing. Isolates were tested for susceptibility to antimicrobial agents by BMD and disk diffusion according to NCCLS guidelines $(11,12)$. Isolates were stored at $-70^{\circ} \mathrm{C}$ and were subcultured to Trypticase soy agar plates containing 5\% defibrinated sheep blood (BD BioSciences, Sparks, Md.) a minimum of two times prior to testing. For each organism, BMD and disk diffusion tests were set up at the same time starting from the same cell suspension equivalent to an $0.5 \mathrm{McF}$ arland standard. CLI and ERY were tested singly and in combination as described below. Concentrations of CLI plus ERY were chosen for the main study based on the results of a pilot study, detailed below.

For disk diffusion testing, one commercially prepared 150-mm-diameter Mueller-Hinton II agar plate (BD BioSciences) was inoculated per organism according to NCCLS guidelines (12). Disks from BD BioSciences containing CLI (2 $\mu \mathrm{g})$ and ERY $(15 \mu \mathrm{g})$ were placed on each Mueller-Hinton plate using a disk dispenser. In addition, on the same Mueller-Hinton plate, an induction test was performed by manually placing a $2-\mu \mathrm{g}$ CLI disk approximately $12 \mathrm{~mm}$ from a $15-\mu \mathrm{g}$ ERY disk (measured edge to edge) as described by Sutcliffe et al. (22) Zone diameters were recorded at 16 to $18 \mathrm{~h}$ for all disks. The results were interpreted using NCCLS guidelines (13). Growth up to a disk (i.e., no zone) was recorded as $6 \mathrm{~mm}$. Induction test results also were read at 16 to $18 \mathrm{~h}$ using transmitted and reflected light. All isolates showing positive induction test results (i.e., a blunted or "D-shaped" zone) and a subset of isolates with other induction test results were read again at $24 \mathrm{~h}$. Induction test categories were recorded as noted in Table 1.

BMD panels were prepared in-house according to NCCLS guidelines (11) using the following concentrations of CLI and ERY in doubling dilutions: CLI, $0.03 \mu \mathrm{g} / \mathrm{ml}$ to $64 \mu \mathrm{g} / \mathrm{ml}$ (USP, Rockville, MD); ERY, $0.06 \mu \mathrm{g} / \mathrm{ml}$ to $128 \mu \mathrm{g} / \mathrm{ml}$ (Lilly, Indianapolis, IN). Combinations of CLI and ERY were tested by BMD in checkerboard fashion using CLI concentrations from 0.5 to $8 \mu \mathrm{g} / \mathrm{ml}$ and ERY concentrations ranging from 0.03 to $4 \mu \mathrm{g} / \mathrm{ml}$. MIC trays were stored at $-70^{\circ} \mathrm{C}$ until the day of use. Testing was performed using NCCLS procedures (11). BMD panels were inoculated using MIC-2000 disposable inoculators (Dynex Technol- ogies, Inc., Chantilly, Va.). Purity check plate assays were performed on all isolates tested by BMD. MICs were read at 16 to $18 \mathrm{~h}$ and interpreted according to NCCLS guidelines (13). For induction testing, each well containing CLI plus ERY was read independently for growth at 16 to $18 \mathrm{~h}$.

Pilot study. To determine which concentrations of CLI plus ERY to use for BMD, we prepared checkerboard microtiter plates as described above using the doubling dilution concentrations of CLI plus ERY. Key test organisms (Table 2) included S. aureus ATCC 29213 (CLI and ERY susceptible), S. aureus HIP11519 (containing $m s r A$ ), S. aureus HIP11502 (containing inducible ermA), and two $S$. aureus clinical isolates from the Centers for Disease Control and Prevention collection (one containing erm $A$ and the other containing erm $C$ by PCR testing). $S$. aureus HIP11502 (ermA) and the clinical isolate containing ermA grew only in wells containing low concentrations of CLI and high concentrations of ERY. The clinical isolate containing erm $\mathrm{C}$ grew in all induction test wells, although less growth was observed in wells containing the highest concentrations of CLI (16 $\mu \mathrm{g} / \mathrm{ml}, 8 \mu \mathrm{g} / \mathrm{ml}$, and $4 \mu \mathrm{g} / \mathrm{ml})$ and the lowest concentration of ERY $(0.12 \mu \mathrm{g} / \mathrm{ml})$. Based on these results, we selected the concentrations of ERY and CLI shown in Table 3 for testing.

Quality control for disk diffusion and BMD. CLI and ERY controls for BMD and disk diffusion testing included Enterococcus faecalis ATCC 29212 (BMD), S. aureus ATCC 29213 (BMD), and S. aureus ATCC 25923 (disk diffusion). Quality control was performed on each testing day; all results were within NCCLS quality control ranges (13). Induction test controls included $S$. aureus HIP11502, S. aureus HIP11519, S. aureus HPV107 (ATCC BAA-44) (19), and S. aureus HDE1 (17). Induction test controls were performed each testing day, and all were in control.

PCR. Organisms were suspended in $100 \mu$ l of ultrapure water and frozen at $-70^{\circ} \mathrm{C}$ until needed. Multiplex reactions for ermA, ermC, and $m s r A$ were performed as previously described $(21,22)$. PCR controls included $S$. aureus RN1551 (ermA), S. aureus RN2442 (ermC), S. aureus RN4220 (msrA), and S. aureus $6520(\mathrm{ermB})(14)$.

\section{RESULTS}

Disk diffusion testing using CLI and ERY. Disk diffusion testing yielded two distinct induction phenotypes and four noninduction phenotypes among the isolates tested (Table 1; Fig. 1). The D-zone phenotype, observed for 21 isolates, showed a blunted edge but an otherwise clear zone of inhibition around the CLI disk. The $\mathrm{D}^{+}$phenotype (17 isolates) showed blunting of the zone of inhibition but also featured small colonies present between the edge of the zone of inhibition and the CLI disk. Both $\mathrm{D}$ and $\mathrm{D}^{+}$results were considered positive for CLI induction (inducible $\mathrm{MLS}_{\mathrm{B}}$ resistance). By PCR, isolates with a $\mathrm{D}$ phenotype contained erm $A$, and isolates with a $\mathrm{D}^{+}$phenotype contained ermC, with or without $\operatorname{erm} A$. Ten isolates showed ERY-resistant and CLI-susceptible zone diameters with no blunting of the zones (Neg phenotype). All 10 contained $m s r A$ by PCR. For 33 isolates, growth was observed 
TABLE 2. Disk diffusion and BMD quality control test results

\begin{tabular}{|c|c|c|c|c|c|c|c|c|}
\hline \multirow[b]{2}{*}{ Parameter } & \multicolumn{3}{|c|}{ Broth microdilution control } & \multirow{2}{*}{$\begin{array}{l}\text { Disk diffusion } \\
\text { control } S \text {. aureus } \\
\text { ATCC } 25923\end{array}$} & \multicolumn{4}{|c|}{ Induction test control } \\
\hline & $\begin{array}{l}\text { Escherichia coli } \\
\text { ATCC } 25922\end{array}$ & $\begin{array}{l}\text { E. faecalis } \\
\text { ATCC } 29212\end{array}$ & $\begin{array}{l}\text { S. aureus } \\
\text { ATCC } 29213\end{array}$ & & $\begin{array}{l}\text { S. aureus } \\
\text { HIP11502 }\end{array}$ & $\begin{array}{l}\text { S. aureus } \\
\text { HIP11519 }\end{array}$ & $\begin{array}{l}\text { S. aureus } \\
\text { HDE1 }\end{array}$ & $\begin{array}{l}\text { S. aureus } \\
\text { HPV107 }\end{array}$ \\
\hline No. of tests & 8 & 8 & 7 & 9 & $9 \mathrm{BMD}, 8$ disk $^{a}$ & $9 \mathrm{BMD}, 7$ disk $^{a}$ & 8 & 8 \\
\hline \multicolumn{9}{|l|}{ Disk } \\
\hline \multicolumn{9}{|c|}{$\begin{array}{l}\text { Zone diam mode } \\
\text { (range) in mm }\end{array}$} \\
\hline ERY & & & & 26 & 7 & 7 & 25 & 6 \\
\hline CLI & & & & 25 & 26 & 26 & 25 & 6 \\
\hline Induction test & & & & $\mathrm{S}$ & $\mathrm{D}$ & Neg & S & HD \\
\hline \multicolumn{9}{|l|}{ BMD } \\
\hline \multicolumn{9}{|l|}{$\begin{array}{l}\mathrm{MIC}_{50}(\text { range }) \\
\text { in } \mu \mathrm{g} / \mathrm{ml}\end{array}$} \\
\hline ERY & 64 & 2 & 0.5 & & $>128$ & 128 & 0.5 & $>128$ \\
\hline CLI & $>64$ & 16 & 0.25 & & 0.25 & 0.12 & 0.25 & $>64$ \\
\hline $\begin{array}{l}\text { Induction test } \\
\text { (CLI/ERY } \\
\text { concn) }\end{array}$ & Not tested & Not tested & No growth & & $\begin{array}{l}\text { CLI } 1+\text { ERY } 4 \text {, } \\
\text { CLI } 1+\text { ERY } 1 \text {, } \\
\text { CLI } 0.5+\text { ERY } 1\end{array}$ & No growth & No growth & $\begin{array}{l}\text { Growth in all } \\
\text { concentra- } \\
\text { tions }\end{array}$ \\
\hline PCR result & Not tested & Not tested & No fragment & Not tested & ermA & $m s r A$ & Not tested & ermA \\
\hline
\end{tabular}

${ }^{a}$ By BMD, nine tests (HIP11502 and HIP11519). By disk diffusion, eight tests (HIP11502) and seven tests (HIP11519).

around both disks, although an inner zone of hazy growth (i.e., a hazy D [HD] phenotype) was visible, which also showed some blunting (Fig. 1). The HD phenotype was not considered indicative of induction since growth extended all the way to the edge of the disk (indicating CLI resistance). By PCR, these isolates contained a variety of $\operatorname{erm} A, \operatorname{erm} C$, and $\operatorname{erm} A$ plus $m s r A$ genes (Table 3). Sixteen isolates showed constitutive ERY and CLI resistance, and confluent growth was noted around both disks ( $\mathrm{R}$ phenotype) with no inner zone of inhibition. These isolates contained erm $A, \operatorname{erm} B, \operatorname{erm} C$, or a combination of genes including $m s r A$ (Table 3 ). Finally, 31 isolates showed large zones of inhibition around both the ERY and CLI disks (S phenotype). Among the control strains, $S$. aureus RN2442 (ermC) showed a $\mathrm{D}^{+}$phenotype, $S$. aureus RN4220 (msr A) showed a Neg phenotype, and $S$. aureus RN1551 (ermA) and $S$. aureus $6520(\mathrm{ermB})$ were both R phenotype, as expected.

For isolates with $\mathrm{D}$ or $\mathrm{D}^{+}$phenotypes, the ranges of the ERY and CLI zone diameters were similar (Table 3). For the D phenotype, 20 of 21 isolates demonstrated a small clear zone of inhibition around the ERY disk (zone diameter, 7 to $8 \mathrm{~mm}$ ), whereas in the $\mathrm{D}^{+}$category, 15 of 17 isolates showed growth up to the ERY disk (6 mm). Although the inducible D zone

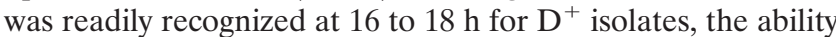
to see the small colonies growing up to the CLI disk was more pronounced at $24 \mathrm{~h}$, particularly when using transmitted light rather than reflected light. For the 10 isolates with the Neg phenotype, the CLI and ERY zone diameters were similar to those of isolates with $\mathrm{D}$ and $\mathrm{D}^{+}$phenotypes (Table 3 ). For most of the 33 isolates with an HD phenotype, the hazy zone around the CLI disk was easy to distinguish from the solid growth up to the CLI disk in the $\mathrm{R}$ phenotype (16 isolates). Visualization of the hazy, D-shaped zone was enhanced using transmitted light. CLI and ERY disks had to be placed $6 \mathrm{~mm}$ apart (edge to edge) to confirm the D shape in one isolate.

BMD testing using CLI and ERY. BMD testing, in which ERY and CLI are placed together in the same microtiter plate well, differentiated among the $\mathrm{S}$ and $\mathrm{Neg}$ ( $m s r A)$ phenotypes (no growth) and the $\mathrm{D}, \mathrm{D}^{+}, \mathrm{HD}$, and $\mathrm{R}$ phenotypes (growth); however, unlike disk diffusion testing, the results did not differentiate among the inducible $\left(\mathrm{D}\right.$ and $\left.\mathrm{D}^{+}\right)$and constitutive (HD and R) phenotypes, since organisms expressing any of these phenotypes grew in the wells containing both ERY and CLI. The MICs of CLI and ERY at which $50 \%$ of the isolates tested were inhibited when tested independently $\left(\mathrm{MIC}_{50} \mathrm{~s}\right)$ were similar for $\mathrm{D}-, \mathrm{D}^{+}-$, and Neg-phenotype isolates (Table 3). Thus, one cannot differentiate CLI-inducible from noninducible isolates solely on the basis of MIC results. The ERY MICs for 2 of 21 isolates with a D phenotype were $8 \mu \mathrm{g} / \mathrm{ml}$, while the remaining $19 \mathrm{D}$-phenotype isolates and all 17 isolates with a $\mathrm{D}^{+}$phenotype showed ERY MICs of $>128 \mu \mathrm{g} / \mathrm{ml}$. The CLI MICs for D-phenotype isolates increased modestly in the presence of ERY, rising from 0.12 or $0.25 \mu \mathrm{g} / \mathrm{ml}$ to $1 \mu \mathrm{g} / \mathrm{ml}$ (which would be interpreted as intermediate) in the presence of 1 or $4 \mu \mathrm{g} / \mathrm{ml}$ of ERY. Thus, induction of isolates with the D phenotype by disk diffusion does not necessarily produce CLI MICs in the resistant range. On the other hand, the CLI MICS of $\mathrm{D}^{+}$isolates rose from 0.12 to $0.25 \mu \mathrm{g} / \mathrm{ml}$ to $8 \mu \mathrm{g} / \mathrm{ml}$ (resistant) in the presence of $0.12 \mu \mathrm{g} / \mathrm{ml}$ of ERY (Table 3). Although several combinations of CLI and ERY in the same well indicated induction of CLI resistance in $\mathrm{D}^{+}$isolates, only a few combinations detected all of the D-phenotype isolates. The combination of $0.5 \mu \mathrm{g} / \mathrm{ml}$ of CLI and $1 \mu \mathrm{g} / \mathrm{ml}$ of ERY identified all D-phenotype isolates in one test, but in repeat testing one D-phenotype isolate failed to grow in this well (Table 3). Testing with a broader array of concentrations, including CLI concentrations of $0.25 \mu \mathrm{g} / \mathrm{ml}$ in conjunction with ERY concentrations of 0.5 to $4 \mu \mathrm{g} / \mathrm{ml}$, identified all D-phenotype isolates (data not shown), but the CLI concentration was very close to the original CLI MICs of the isolates. Thus, differentiating D-phenotype isolates from other phenotypes by BMD testing is difficult. There was no difference in CLI and ERY MICs among isolates with HD and $\mathrm{R}$ phenotypes, which also grew in all induction test wells containing CLI and ERY. Isolates with an S phenotype were susceptible to CLI and ERY by MIC testing and did not grow in any induction test well. 
TABLE 3. Characteristics of isolates categorized by disk diffusion induction test phenotype

\begin{tabular}{|c|c|c|c|c|c|c|}
\hline \multirow{2}{*}{ Parameter } & \multicolumn{6}{|c|}{ Disk diffusion phenotype } \\
\hline & $\mathrm{D}$ & $\mathrm{D}^{+}$ & Neg & HD & $\mathrm{R}$ & $\mathrm{S}$ \\
\hline No. of isolates & 21 & 17 & 10 & 33 & 16 & 31 \\
\hline \multicolumn{7}{|l|}{$\begin{array}{l}\text { Disk zone mode (range) } \\
\text { in } \mathrm{mm}\end{array}$} \\
\hline ERY & $7(6-8)$ & $6(6-7)$ & $6(6-10)$ & $6(6)$ & $6(6)$ & $25(20-28)$ \\
\hline CLI & $25(22-30)$ & $25(23-30)$ & $24(23-31)$ & $6(6)$ & $6(6)$ & $24(23-31)$ \\
\hline \multicolumn{7}{|l|}{$\begin{array}{l}\text { BMD } \mathrm{MIC}_{50} \text { (range) } \\
\text { in } \mu \mathrm{g} / \mathrm{ml}\end{array}$} \\
\hline ERY & $>128(8->128)$ & $>128(>128)$ & $128(8-128)$ & $>128(>128)$ & $>128(>128)$ & $0.5(0.5-1)$ \\
\hline CLI & $0.25(0.12-0.25)$ & $0.25(0.12-0.25)$ & $0.12(0.12-0.25)$ & $>64(>64)$ & $>64(>64)$ & $0.12(0.12-0.25)$ \\
\hline \multicolumn{7}{|l|}{$\begin{array}{l}\text { No. of isolates that grew } \\
\text { in medium }\end{array}$} \\
\hline \multicolumn{7}{|l|}{ CLI, $8 \mu \mathrm{g} / \mathrm{ml}$, plus } \\
\hline ERY, $0.12 \mu \mathrm{g} / \mathrm{ml}$ & 0 & 17 & 0 & 33 & 16 & 0 \\
\hline ERY, $0.06 \mu \mathrm{g} / \mathrm{ml}$ & 0 & 16 & 0 & 33 & 16 & 0 \\
\hline ERY, $0.03 \mu \mathrm{g} / \mathrm{ml}$ & 0 & 4 & 0 & 33 & 16 & 0 \\
\hline \multicolumn{7}{|l|}{ CLI, $4 \mu \mathrm{g} / \mathrm{ml}$, plus } \\
\hline ERY, $0.12 \mu \mathrm{g} / \mathrm{ml}$ & 0 & 17 & 0 & 33 & 16 & 0 \\
\hline ERY, $0.06 \mu \mathrm{g} / \mathrm{ml}$ & 0 & 16 & 0 & 33 & 16 & 0 \\
\hline ERY, $0.03 \mu \mathrm{g} / \mathrm{ml}$ & 0 & 7 & 0 & 33 & 16 & 0 \\
\hline \multicolumn{7}{|l|}{ CLI, $2 \mu \mathrm{g} / \mathrm{ml}$, plus } \\
\hline ERY, $0.12 \mu \mathrm{g} / \mathrm{ml}$ & 0 & 17 & 0 & 33 & 16 & 0 \\
\hline ERY, $0.06 \mu \mathrm{g} / \mathrm{ml}$ & 0 & 17 & 0 & 33 & 16 & 0 \\
\hline ERY, $0.03 \mu \mathrm{g} / \mathrm{ml}$ & 0 & 15 & 0 & 33 & 16 & 0 \\
\hline \multicolumn{7}{|l|}{ CLI, $1 \mu \mathrm{g} / \mathrm{ml}$, plus } \\
\hline ERY, $4 \mu \mathrm{g} / \mathrm{ml}$ & 20 & 17 & 0 & 33 & 16 & 0 \\
\hline ERY, $1 \mu \mathrm{g} / \mathrm{ml}$ & 17 & 17 & 0 & 33 & 16 & 0 \\
\hline $\begin{array}{l}\text { CLI, } 0.5 \mu \mathrm{g} / \mathrm{ml} \text {, plus } \\
\text { ERY, } 1 \mu \mathrm{g} / \mathrm{ml}\end{array}$ & $21^{a}$ & 17 & 0 & 33 & 16 & 0 \\
\hline $\begin{array}{l}\text { PCR result (no. of } \\
\text { isolates) }\end{array}$ & $\operatorname{erm} A(21)$ & $\begin{array}{l}\operatorname{erm} C(16), \text { erm } C+ \\
\quad \text { ermA (1) }\end{array}$ & $m s r A(10)$ & $\begin{array}{l}\operatorname{erm} A(31), \operatorname{erm} A+ \\
\quad m s r A(1), \text { erm } C \\
\quad(1)\end{array}$ & $\begin{array}{l}\text { erm } A(8), \operatorname{erm} A+ \\
\quad \text { erm } C(3), \text { erm } A+ \\
\text { msrA (1), ermB } \\
\quad(1), \operatorname{erm} C(3)\end{array}$ & \\
\hline $\begin{array}{l}\text { Oxacillin interpretation } \\
\text { (no. of isolates) }\end{array}$ & S (5), R (16) & S (8), R (9) & S (2), R (8) & S (2), R (31) & S (3), R (13) & $\mathrm{S}(18), \mathrm{I}^{b} \& \mathrm{R}(13)$ \\
\hline
\end{tabular}

${ }^{a}$ One isolate was not detected as inducible on repeat testing.

${ }^{b} \mathrm{I}$, intermediate.

\section{DISCUSSION}

Our CLI induction results for disk diffusion testing showed two phenotypes, each of which had distinct blunting of the zone of inhibition proximal to the ERY disk, one with a clear zone of inhibition (D phenotype) and the other with small colonies within the zone of inhibition $\left(\mathrm{D}^{+}\right.$phenotype). Interestingly, the small colonies in the $\mathrm{D}^{+}$zone were constitutively resistant to clindamycin when retested. While there is no clinical significance to the differences between $\mathrm{D}$ and $\mathrm{D}^{+}$phenotypes, it is critical that microbiologists recognize that both phenotypes are considered to be positive D-zone test results. The $\mathrm{D}^{+}$phenotype has not been well described in the recent literature regarding inducible clindamycin resistance. An older study by Jenssen et al. (5) also reported two types of inducible $\mathrm{MLS}_{\mathrm{B}}$ resistance phenotypes, although only a limited number of inducibly resistant isolates were tested. In that study, the MLS type 1 and the MLS type 2 phenotypes correlated with the presence of erm $A$ and erm $C$, respectively. Our study supports the conclusions of Jenssen et al. that disk diffusion can be used to predict the organism's genotype, although as noted here isolates may harbor two or more macrolide resistance genes. Of the 128 isolates in this study, six (5\%) contained multiple macrolide resistance determinants.

Positive disk diffusion induction results $\left(\mathrm{D}\right.$ and $\left.\mathrm{D}^{+}\right)$could be read at 16 to $18 \mathrm{~h}$ using reflected light; however, transmitted light improved the ability to separate some noninducible phenotypes, such as HD and R. Continued incubation of disk tests up to $24 \mathrm{~h}$ also helped differentiate $\mathrm{D}(\mathrm{erm} A)$ from $\mathrm{D}^{+}(\mathrm{ermC})$ phenotypes, but the additional incubation time was not necessary to distinguish between CLI-inducible and noninducible isolates. BMD induction results were also available in 16 to $18 \mathrm{~h}$. BMD incubation times up to $24 \mathrm{~h}$ did not result in detection of additional CLI-inducible isolates.

Most of the published induction test studies focus on identifying inducible CLI resistance among isolates that are ERY resistant but CLI susceptible on routine testing $(18,26,27)$. We agree that in principle only ERY-resistant but CLI-susceptible isolates should be tested; however, some laboratories perform the D-zone test prospectively on susceptibility testing purity plates before the results of erythromycin and clindamycin resistance are known. Thus, we tested a number of isolates that were either resistant or susceptible to both ERY and CLI to 
A

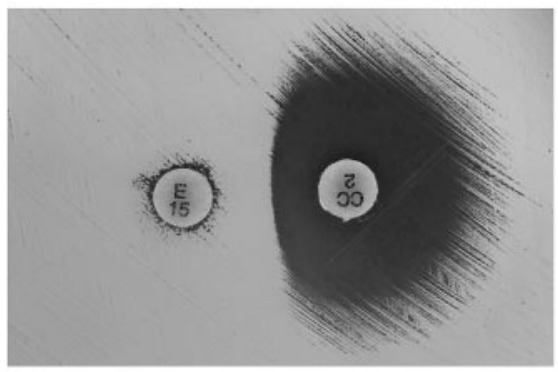

D

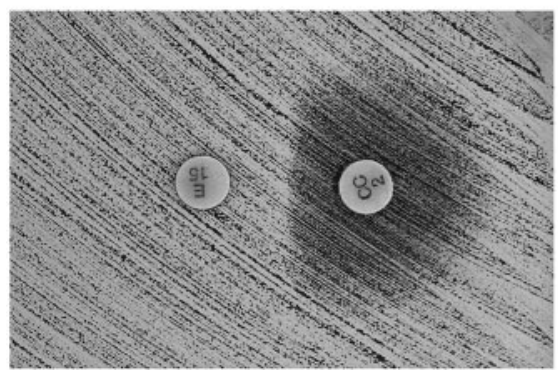

$\mathbf{B}$

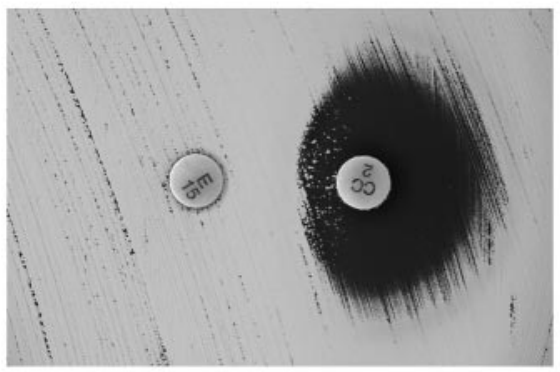

$\mathbf{E}$

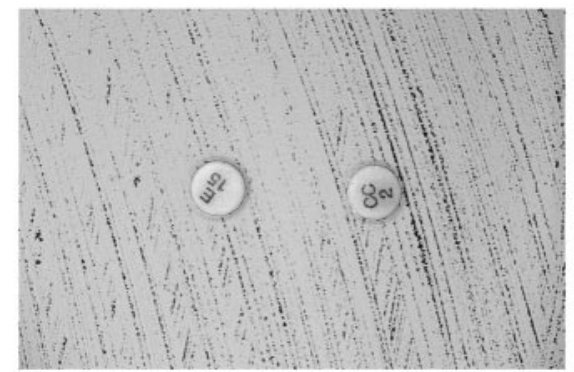

C

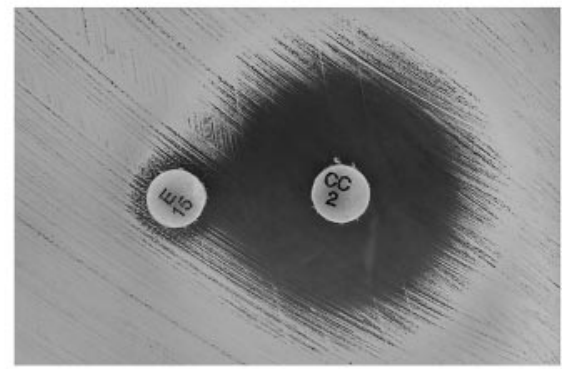

$\mathbf{F}$

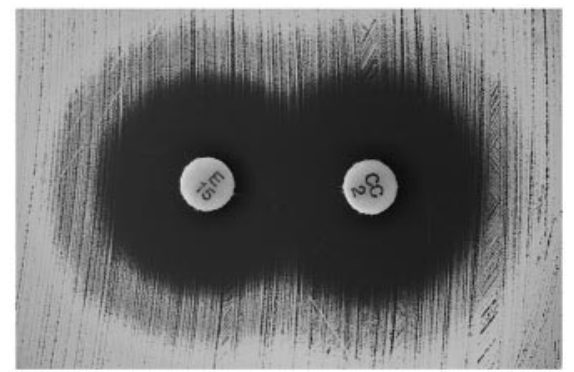

FIG. 1. This figure shows the six phenotypes observed during CLI induction testing of $S$. aureus by disk diffusion. E 15 , ERY disk (15 $\mu \mathrm{g})$; CC 2, CLI disk $(2 \mu \mathrm{g})$. Top row: D phenotype (A), $\mathrm{D}^{+}$phenotype (B), Neg phenotype (C). Bottom row: HD phenotype (D), R phenotype (E), S phenotype $(\mathrm{F})$. See text and Table 1 for descriptions of the phenotypes.

determine (i) if there were other novel phenotypes that may be confused with clindamycin induction and (ii) to see if the phenotypic results would also predict the genotype of the isolates. In fact, the HD zone is a phenotype that may be confused with clindamycin induction if the clindamycin test is not initially interpreted to be resistant. As to the relationship of phenotype and genotype, due to the presence of multiple macrolide resistance determinants in our isolates, the predictions were not absolute. For the clinical laboratory, the differentiation of erm-mediated inducible $\mathrm{MLS}_{\mathrm{B}}$ (D and $\mathrm{D}^{+}$phenotypes) isolates from isolates with $m s r A$-mediated (Neg-phenotype) resistance is the critical issue because of the therapeutic implications of using CLI to treat a patient with an inducibly CLIresistant $S$. aureus isolate. However, differentiating $\mathrm{D}$ from $\mathrm{D}^{+}$ phenotypes could also provide information to help characterize isolates for epidemiologic studies in healthcare and community settings. The D-zone test should not be set up on strains that are already known to be resistant to both ERY and CLI.

The BMD induction test also worked well in differentiating $\mathrm{D}$ and $\mathrm{D}^{+}$isolates from Neg-phenotype isolates, but identifying the optimal concentrations of ERY and CLI to use will likely require further study, particularly if laboratories wish to use only a single well for screening for CLI induction. In our study, only the combination of $0.5 \mu \mathrm{g} / \mathrm{ml}$ of CLI and $1 \mu \mathrm{g} / \mathrm{ml}$ of ERY was effective in differentiating the $\mathrm{D}_{-}, \mathrm{D}^{+}-$, HD-, and R-phenotype isolates (growth) from the Neg- and S-phenotype isolates (no growth). However, many of the D-phenotype isolates did not grow with other concentrations of ERY and CLI. On repeat BMD testing, one D-phenotype isolate was not detected in the well with $0.5-\mu \mathrm{g} / \mathrm{ml}$ CLI and $1-\mu \mathrm{g} / \mathrm{ml}$ ERY.
Additional studies in multiple laboratories will likely be required to identify the optimal concentrations of CLI and ERY to detect CLI-inducible isolates by BMD. This approach, once standardized, may be especially helpful to clinical laboratories that use automated susceptibility testing systems.

In this study, which was completed prior to publication of the NCCLS recommendations for clindamycin induction testing, the CLI and ERY disks for the disk diffusion induction testing were placed $12 \mathrm{~mm}$ apart (edge to edge), as described by Sutcliffe et al. for testing pneumococci (22). NCCLS currently recommends placing the CLI and ERY disks anywhere from 15 to $26 \mathrm{~mm}$ apart (13). Recent papers suggest that distances up to $28 \mathrm{~mm}$ will work for $S$. aureus and most coagulase-negative staphylococci $(3,6)$. However, our experience suggests that induction test results are more difficult to read as the CLI and ERY disks are placed further and further apart. We have limited experience in testing coagulase-negative staphylococci but have noted that the tests are much more difficult to interpret when the disk are placed more than $20 \mathrm{~mm}$ apart.

NCCLS will likely recommend two new quality assessment strains for CLI induction testing, ATCC BAA-977, which contains $\operatorname{erm} A$, and ATCC BAA-976, which contains $m s r A$. Neither strain was tested in this study. Rather, four in-house strains provided quality assessment information for the six induction test phenotypes. For routine testing in a clinical laboratory, however, only an ermA- or erm $C$-containing isolate that produces a positive D-zone test (e.g., ATCC BAA-977) and an $m s r A$-containing isolate that produces a negative $\mathrm{D}$-zone test (e.g., ATCC BAA-976) are necessary. 


\section{ACKNOWLEDGMENTS}

We thank Jasmine Chaitram, Jana Swenson, and Linda Weigel for helpful discussions.

Phase IV of Project ICARE is supported in part by unrestricted grants to the Rollins School of Public Health of Emory University by Abbott Laboratories, Abbott Park, IL; Astra-Zeneca Pharmaceuticals, Wilmington, DE; Bayer Corporation, Pharmaceuticals Division, West Haven, CT; Cubist Pharmaceuticals, Inc., Lexington, MA; Elan Pharmaceuticals, San Diego, CA; Pfizer Incorporated, New York, NY; and Roche Laboratories, Nutley, NJ.

Use of trade names is for identification purposes only and does not constitute endorsement by the Public Health Service or the U.S. Department of Health and Human Services.

\section{REFERENCES}

1. Brisson-Noel, A., P. Delrieu, D. Samain, and P. Courvalin. 1988. Inactivation of lincosaminide antibiotics in Staphylococcus. Identification of lincosaminide O-nucleotidyltransferases and comparison of the corresponding resistance genes. J. Biol. Chem. 263:15880-15887.

2. Drinkovic, D., E. R. Fuller, K. P. Shore, D. J. Holland, and R. Ellis-Pegler. 2001. Clindamycin treatment of Staphylococcus aureus expressing inducible clindamycin resistance. J. Antimicrob. Chemother. 48:315-316.

3. Fiebelkorn, K. R., S. A. Crawford, M. L. McElmeel, and J. H. Jorgensen. 2003. Practical disk diffusion method for detection of inducible clindamycin resistance in Staphylococcus aureus and coagulase-negative staphylococci. J. Clin. Microbiol. 41:4740-4744.

4. Fridkin, S. K., C. D. Steward, J. R. Edwards, E. R. Pryor, J. E. McGowan, Jr., L. K. Archibald, R. P. Gaynes, F. C. Tenover, and Project Intensive Care Antimicrobial Resistance Epidemiology (ICARE) Hospitals. 1999. Surveillance of antimicrobial use and antimicrobial resistance in United States hospitals: Project ICARE phase 2. Clin. Infect. Dis. 29:245-252.

5. Jenssen, W. D., S. Thakker-Varia, D. T. Dubin, and M. P. Weinstein. 1987 Prevalence of macrolides-lincosamides-streptogramin B resistance and erm gene classes among clinical strains of staphylococci and streptococci. Antimicrob. Agents Chemother. 31:883-888

6. Jorgensen, J. H., S. A. Crawford, M. L. McElmeel, and K. R. Fiebelkorn. 2004. Detection of inducible clindamycin resistance of staphylococci in conjunction with performance of automated broth susceptibility testing. J. Clin. Microbiol. 42:1800-1802.

7. Leclercq, R. 2002. Mechanisms of resistance to macrolides and lincosamides: nature of the resistance elements and their clinical implications. Clin. Infect. Dis. 34:482-492.

8. Leclercq, R., A. Brisson-Noel, J. Duval, and P. Courvalin. 1987. Phenotypic expression and genetic heterogeneity of lincosamide inactivation in Staphylococcus spp. Antimicrob. Agents Chemother. 31:1887-1891.

9. Leclercq, R., and P. Courvalin. 1991. Bacterial resistance to macrolide, lincosamide, and streptogramin antibiotics by target modification. Antimicrob. Agents Chemother. 35:1267-1272.

10. McGowan, J. E., Jr., H. A. Hill, N. V. Volkova, R. M. Lawton, M. J. Haber, F. C. Tenover, and R. P. Gaynes. 2002. Does antimicrobial resistance cluster in individual hospitals? J. Infect. Dis. 186:1362-1365.

11. NCCLS. 2000. Methods for dilution antimicrobial susceptibility tests fo bacteria that grow aerobically; approved standard, 5th edition. NCCLS document M7-A5. NCCLS, Wayne, Pa.

12. NCCLS. 2000. Performance standards for antimicrobial disk susceptibil- ity tests; approved standard, 7th ed. Approved standard M2-A7. NCCLS, Wayne, Pa.

13. NCCLS. 2004. Performance standards for antimicrobial susceptibility testing: 12th informational supplement. NCCLS document M100-S14. NCCLS, Wayne, Pa.

14. Nicola, F. G., L. K. McDougal, J. W. Biddle, and F. C. Tenover. 1998. Characterization of erythromycin-resistant isolates of Staphylococcus aureus recovered in the United States from 1958 through 1969. Antimicrob. Agents Chemother. 42:3024-3027.

15. Roberts, M. C., J. Sutcliffe, P. Courvalin, L. B. Jensen, J. Rood, and H. Seppala. 1999. Nomenclature for macrolide and macrolide-lincosamidestreptogramin B resistance determinants. Antimicrob. Agents Chemother. 43:2823-2830.

16. Ross, J. I., E. A. Eady, J. H. Cove, W. J. Cunliffe, S. Baumberg, and J. C. Wootton. 1990. Inducible erythromycin resistance in staphylococci is encoded by a member of the ATP-binding transport super-gene family. Mol. Microbiol. 4:1207-1214.

17. Sa-Leao, R., I. Santos Sanches, D. Dias, I. Peres, R. M. Barros, and H. de Lencastre. 1999. Detection of an archaic clone of Staphylococcus aureus with low-level resistance to methicillin in a pediatric hospital in Portugal and in international samples: relics of a formerly widely disseminated strain? J. Clin. Microbiol. 37:1913-1920.

18. Sanchez, M. L., K. K. Flint, and R. N. Jones. 1993. Occurrence of macrolidelincosamide-streptogramin resistances among staphylococcal clinical isolates at a university medical center. Is false susceptibility to new macrolides and clindamycin a contemporary clinical and in vitro testing problem? Diagn. Microbiol. Infect. Dis. 16:205-213

19. Santos Sanches, I., M. Ramirez, H. Troni, M. Abecassis, M. Padua, A. Tomasz, and H. de Lencastre. 1995. Evidence for the geographic spread of a methicillin-resistant Staphylococcus aureus clone between Portugal and Spain. J. Clin. Microbiol. 33:1243-1246.

20. Siberry, G. K., T. Tekle, K. Carroll, and J. Dick. 2003. Failure of clindamycin treatment of methicillin-resistant Staphylococcus aureus expressing inducible clindamycin resistance in vitro. Clin. Infect. Dis. 37:1257-1260.

21. Sutcliffe, J., T. Grebe, A. Tait-Kamradt, and L. Wondrack. 1996. Detection of erythromycin-resistant determinants by PCR. Antimicrob. Agents Chemother. 40:2562-2566.

22. Sutcliffe, J., A. Tait-Kamradt, and L. Wondrack. 1996. Streptococcus pneumoniae and Streptococcus pyogenes resistant to macrolides but sensitive to clindamycin: a common resistance pattern mediated by an efflux system. Antimicrob. Agents Chemother. 40:1817-1824.

23. Thakker-Varia, S., W. D. Jenssen, L. Moon-McDermott, M. P. Weinstein, and D. T. Dubin. 1987. Molecular epidemiology of macrolides-lincosamidesstreptogramin B resistance in Staphylococcus aureus and coagulase-negative staphylococci. Antimicrob. Agents Chemother. 31:735-743.

24. Watanakunakorn, C. 1976. Clindamycin therapy of Staphylococcus aureus endocarditis. Clinical relapse and development of resistance to clindamycin, lincomycin and erythromycin. Am. J. Med. 60:419-425.

25. Weisblum, B. 1995. Erythromycin resistance by ribosome modification. Antimicrob. Agents Chemother. 39:577-585.

26. Westh, H., D. M. Hougaard, J. Vuust, and V. T. Rosdahl. 1995. Prevalence of erm gene classes in erythromycin-resistant Staphylococcus aureus strains isolated between 1959 and 1988. Antimicrob. Agents Chemother. 39:369373.

27. Wondrack, L., M. Massa, B. V. Yang, and J. Sutcliffe. 1996. Clinical strain of Staphylococcus aureus inactivates and causes efflux of macrolides. Antimicrob. Agents Chemother. 40:992-998. 